\title{
A Public-Domain Personality Item Bank For Use With The Raymark, Schmit, and Guion (1997) PPRF
}

\author{
Scott Highhouse \\ Bowling Green State University \\ Michael J. Zickar \\ Bowling Green State University \\ Margaret E. Brooks \\ Bowling Green State University \\ Charlie L. Reeve \\ University of North Carolina - Charlotte \\ Shreya T. Sarkar-Barney \\ Human Capital Growth \\ Follow this and additional works at: https://scholarworks.bgsu.edu/pad \\ Part of the Human Resources Management Commons, Industrial and Organizational Psychology \\ See next page for additional authors \\ Commons, and the Other Psychology Commons \\ How does access to this work benefit you? Let us know!
}

\section{Recommended Citation}

Highhouse, Scott; Zickar, Michael J.; Brooks, Margaret E.; Reeve, Charlie L.; Sarkar-Barney, Shreya T.; and Guion, Robert M. (2016) "A Public-Domain Personality Item Bank For Use With The Raymark, Schmit, and Guion (1997) PPRF," Personnel Assessment and Decisions: Number 2 : Iss. 1 , Article 5.

DOI: https://doi.org/10.25035/pad.2016.005

Available at: https://scholarworks.bgsu.edu/pad/vol2/iss1/5

This Measurement and Measures is brought to you for free and open access by the Journals at ScholarWorks@BGSU. It has been accepted for inclusion in Personnel Assessment and Decisions by an authorized editor of ScholarWorks@BGSU. 


\section{A Public-Domain Personality Item Bank For Use With The Raymark, Schmit, and Guion (1997) PPRF}

\section{Authors}

Scott Highhouse, Michael J. Zickar, Margaret E. Brooks, Charlie L. Reeve, Shreya T. Sarkar-Barney, and Robert M. Guion 


\title{
A Public-Domain Personality Item Bank FOR USE WITH THE Raymark, Schmit, and Guion (1997) PPRF
}

\author{
Scott Highhouse ${ }^{1}$, Michael J. Zickar ${ }^{1}$, Margaret E. Brooks ${ }^{1}$, \\ Charlie L. Reeve ${ }^{2}$, Shreya T. Sarkar-Barney ${ }^{3}$, and Robert M. Guion ${ }^{1}$ \\ 1. Bowling Green State University \\ 2. University of North Carolina - Charlotte \\ 3. Human Capital Growth
}

ABSTRACT

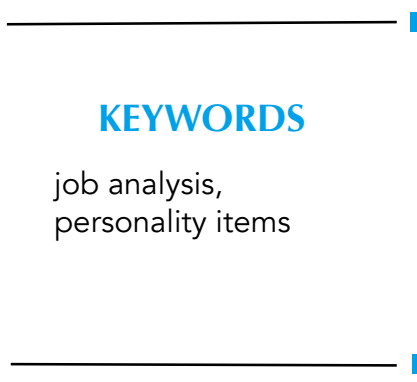

Presented is the development of a repository of work-related personality items that may be used to assess job-related traits identified by the Personality-Related Position Requirements Form (PPRF: Raymark, Schmit, \& Guion, 1997). Analyses of the item pool administered to a sample $(n=412)$ of trade apprentices showed evidence to support the 12 work-related Big 5 sub-dimensions identified by the PPRF. A smaller validity study ( $n$ $=47$ ) suggested that personality dimensions identified as job related by the PPRF were related to important job-related outcomes.
Raymark, Schmit, and Guion (1997) developed the Personality-Related Position Requirements Form (PPRF), a public-domain job-analysis inventory specifically intended to map behavioral job requirements onto work-related personality traits. The goal of the PPRF was to allow one to establish the job-relatedness of personality assessment by having job experts determine whether effective performance on a specific job requires people to engage in various behavioral items (e.g., interact with clients, customers, or coworkers) that were developed to correspond to personality traits. These behavioral items are rated by job experts as not required, helpful, or essential to performance on the job in question. The PPRF was designed to be a public-domain job analysis instrument that could be used by both researchers and practitioners to make better decisions about matching personality dimensions to the specific needs of the job. According to the authors: "At this point, the PPRF is offered to researchers and practitioners so that improvements, refinements, and additional tests of the efficacy of the instrument in generating hypotheses can be conducted on a broad front" (Raymark et al., 1997; p. 735). The PPRF job-analysis instrument can be obtained using this link: https://www.bgsu.edu/arts-and-sciences/psychology/services/personality-related-position-requirements-form-.html.

Unfortunately, Raymark et al's (1997) initial hopes for improvements and refinements have yet to come to fruition. Indeed, the PPRF has been largely neglected in the research domain. It has been cited only 165 times over nearly 2 decades, and there is little to indicate that the instrument has been widely adopted in practice (Goffin et al., 2011). According to Goffin and colleagues, the contextual dimensions used by the PPRF do not map well to existing personality instruments, and thus we lack evidence showing that the traits identified as job relevant by the PPRF have greater criterion-related validity than traits identified as job irrelevant.

This paper is aimed at beginning to address these concerns by providing a public-domain pool of personality items that map on to the PPRF dimensions. We suggest that this may serve as a repository of test items that can be used to assess job-related traits identified by the PPRF or other personality-based job analysis method.

From a research perspective, we provide an alternative to the International Personality Item Pool (IPIP; Goldberg, 1999) - a widely used set of personality items in the public domain. Moreover, our item pool has the added benefit of being work-related and mapping directly on to a personality-based job analysis instrument. From a practice perspective, we provide a repository of items for developing scales that may be used in concert with the PPRF, something that has been heretofore missing in the literature (Goffin et al., 2011).

\section{Corresponding author:}

Scott Highhouse

Bowling Green State University

Department of Psychology, 43403

Email: shighho@bgsu.edu 


\section{PPRF and the Big Five}

Although the job-related behaviors for the PPRF were developed inductively, the five-factor model of personality (the Big Five; Saucier \& Goldberg, 1996) was used as a taxonomy to sort the behaviors (Raymark et al., 1997). Following this, the researchers logically sorted the work behaviors into meaningful subfactors of the Big Five, forming the 12 dimensions of the PPRF. Table 1 presents the 12 PPRF dimensions along with sample PPRF behavioral statements that represent these subfactors. The table also shows which Big Five factors are represented by each dimension. Note that the Big Five trait "Emotional Stability" does not have multiple subfactors and, as such, is represented as both a factor of the Big Five and one of the 12 PPRF dimensions. Research reported by Raymark and colleagues (1997) showed that 11 of the 12 dimensions of the job analysis inventory had internal consistency reliability above .70, interrater agreement ranged from .66 to .92 , and the 12 dimensions were useful for discriminating among occupational groups containing 260 jobs. The developers of the PPRF, therefore, demonstrated the utility of the dimensions for describing jobs.

The PPRF developers left open the question, however, of how to match personality items to the dimensionsand whether dimensions identified as job related would successfully predict performance. According to Raymark et al. (1997), "Nevertheless, evidence should be accumulated to show whether hypotheses developed with the help of the PPRF tend to be supported in practical use" (p. 734). Our goal in this study was to create a pool of work-related personality items, based on the PPRF dimensional structure, to provide a way for people to begin answering these questions.

\section{Development of the Item Pool}

The IPIP (Goldberg, 1999; http://ipip.ori.org) created a repository of personality items that could serve as a starting point for identifying items that map on to the PPRF. A five-member research group, led by Robert M. Guion and comprising of industrial-organizational psychology faculty and doctoral students at Bowling Green State University, independently identified IPIP items that were deemed fitting for each of the original 12 PPRF dimensions (see Table 1). Statements from each of the five general factors (e.g., Agreeableness) were allocated to the specific PPRF subdimension (e.g., collaborative work tendency) that appeared most appropriate. In choosing statements that corresponded with the PPRF dimensions, preference was to be given to statements with clear relevance to work settings rather than to social events or to life in general. Because the general factor Emotional Stability has just one PPRF dimension (emotional stability), items for the dimension were chosen according to their apparent relevance to behavior at work.

Discussion focused on those IPIP statements that at least two members had allocated to the PPRF subdimension. An initial item pool began with the selection of marker items and other IPIP items considered good fits as written (e.g., "I see myself as a good leader"). Some IPIP items were reworded to fit the PPRF definitions better, and some new items were written from scratch (e.g., "I can organize people to get things done"). It should be noted that most of the items are "new" items - items written by group mem-

TABLE 1.

PPRF Dimensions Corresponding to Big Five and Associated PPRF Items

\begin{tabular}{|c|c|c|}
\hline Big Five factor & PPRF dimension & Sample PPRF item \\
\hline \multirow[t]{3}{*}{ I. Extraversion } & A. General leadership & ...delegate to others the authority to get something done \\
\hline & B. Interest in negotiation & $\begin{array}{l}\text {...work with dissatisfied customers or clients to achieve a mutually } \\
\text { agreeable solution }\end{array}$ \\
\hline & C. Achievement striving & $\begin{array}{l}\text {... persevere in the pursuit of his or her own work goals even when } \\
\text { unsuccessful }\end{array}$ \\
\hline \multirow[t]{3}{*}{ II. Agreeableness } & A. Friendly disposition & ... arrange and host work-related social activities \\
\hline & B. Sensitivity to others & ...listen attentively to the work-related problems of others \\
\hline & C. Collaborative work tendency & ...work with one or more coworkers to complete assigned tasks \\
\hline \multirow[t]{3}{*}{ III. Conscientiousness } & A. General trustworthiness & ...manage large sums of money on behalf of the organization \\
\hline & B. Adherence to work ethic & ...work effectively and consistently with little or no supervision \\
\hline & C. Attention to details & $\begin{array}{l}\text {...examine all aspects of written reports to be sure that nothing has } \\
\text { been omitted }\end{array}$ \\
\hline \multicolumn{2}{|c|}{ IV. Emotional Stability A. Emotional stability } & ...work under conditions that are potentially emotionally stressful \\
\hline V. Openness to & A. Desire to generate ideas & ...suggest new products, product lines, or new types of services \\
\hline Experience & $\begin{array}{l}\text { B. Tendency to think things } \\
\text { through }\end{array}$ & $\begin{array}{l}\text {...review all relevant information about previous projects to be sure } \\
\text { that planning for new ones considers important prior experiences. }\end{array}$ \\
\hline
\end{tabular}


bers or items suggested by but different from items in the IPIP list. This pool of items was administered to psychology undergraduates $(n=342)$. Responses were analyzed for scale intercorrelations, item-total correlations within scales (i.e., PPRF dimensions), and item correlations with other scales. Items and item statistics were examined within each dimension during group discussion. Those with low item-total correlations or too highly correlated with other dimensions were discarded. The final pool of 170 items is presented in the Appendix and may also be obtained using this link: https://www.bgsu.edu/arts-and-sciences/ psychology/services/personality-related-position-requirements-form-.html.

\section{Analyses on Applicant Sample}

We administered all personality items to applicants for mechanical service apprenticeships in several local building trade unions $(n=412)$. The vast majority $(93 \%)$ of the applicants were male, with an average age of 29. Respondents were asked to indicate how accurate each item is in describing them. Responses range from $1=$ very inaccurate to $5=$ very accurate. Participants completed the items online and were told that their responses would be used for research purposes only.

Item analyses. Table 2 shows the means, standard deviations, and alphas for the personality scales mapping onto the 12 dimensions of the PPRF. This table shows that each of the 12 factors had strong internal consistency. Table 3 shows the intercorrelations of the 12 dimensions.

Table 4 shows the results of confirmatory factor analysis (CFA) for each of the Big Five traits. Recall that the PPRF identifies three dimensions for Extraversion, Agree- ableness, and Conscientiousness. It identifies one dimension for Emotional Stability, and two dimensions for Openness to Experience. The CFAs were conducted to determine fit of the personality scales to these hypothesized models. As shown in Table 4, the hypothesized models provided reasonable fit with the data. For instance, the smaller RMSEA indicates better fit. In contrast, the relatively higher values for TLI and CFI represent better fit. Finally, a value of SRMR less than .08 is generally considered a good fit (Hu \& Bentler, 1999). In addition, a parallel analysis, in conjunction with exploratory analysis, supported the hypothesized structure within each of the Big Five categories. For example, three factors were found for the Extraversion scale and one factor was found for the Emotional Stability scale.

Validity study. We conducted a validity study on a subset of the apprentices $(n=47)$ who completed training in heating, air conditioning, and mechanical-equipment service for the trade union. Records were examined related to their scores and grades in the apprenticeship class (i.e., customer service), records of absenteeism, and discipline actions. Table 5 shows the relation between the 12 personality dimensions and the various outcomes. The highest validities were observed for the Conscientiousness dimensions (i.e., general trustworthiness, adherence to work ethic, attention to details).

In order to examine whether personality dimensions identified as important by the PPRF were more valid than those not identified as important, we administered the PPRF (behavioral statements) to nine subject matter experts (SMEs) from the trade union. These people included the trainers in the apprenticeship program. Table 5 shows, by dimension, the percentage of PPRF behavioral statements

TABLE 2.

Personality Item Means, Standard Deviations, and Alphas

\begin{tabular}{|c|c|c|c|c|}
\hline Big Five factor & PPRF dimension & Sample personality item & Mean (SD) & $\begin{array}{c}\text { Cronbach's } \\
\text { alpha }\end{array}$ \\
\hline \multirow[t]{3}{*}{ I. Extraversion } & A. General leadership & I can inspire people to follow me & $3.64(.55)$ & .89 \\
\hline & B. Interest in negotiation & I can see common ground in opposing views & $3.66(.51)$ & .85 \\
\hline & C. Achievement striving & I value personal achievement & $4.41(.43)$ & .87 \\
\hline \multirow[t]{3}{*}{ II. Agreeableness } & A. Friendly disposition & I enjoy the company of others & $4.09(.56)$ & .90 \\
\hline & B. Sensitivity to others & I feel others' emotions & $3.76(.59)$ & .90 \\
\hline & $\begin{array}{l}\text { C. Collaborative work } \\
\text { tendency }\end{array}$ & Team success is important to me & $4.06(.53)$ & .87 \\
\hline \multirow[t]{3}{*}{ III. Conscientiousness } & A. General trustworthiness & People know I tell the truth & $4.49(.48)$ & .87 \\
\hline & B. Adherence to work ethic & I can be counted on & $4.21(.50)$ & .87 \\
\hline & C. Attention to details & I pay attention to details others might overlook & $4.07(.50)$ & .85 \\
\hline IV. Emotional Stability & A. Emotional stability & I am relaxed most of the time & $3.62(.62)$ & .88 \\
\hline V. Openness to & A. Desire to generate ideas & I think up new ideas & $4.00(.54)$ & .89 \\
\hline Experience & $\begin{array}{l}\text { B. Tendency to think } \\
\text { things through }\end{array}$ & I spend time reflecting on things & $3.78(.47)$ & .79 \\
\hline
\end{tabular}


TABLE 3.

Personality Dimension Intercorrelations

\begin{tabular}{|c|c|c|c|c|c|c|c|c|c|c|c|}
\hline & 2 & 3 & 4 & 5 & 6 & 7 & 8 & 9 & 10 & 11 & 12 \\
\hline 1. Leadership & $.53 * *$ & $.51 * *$ & $.30 * *$ & $.27 * *$ & $.35 * *$ & $.29 * *$ & $.44 * *$ & $.45 * *$ & $.17 * *$ & $.53 * *$ & $.34 * *$ \\
\hline 2. Negotiation & & $.48 * *$ & $.56 * *$ & $.66 * *$ & $.55 * *$ & $.42 * *$ & $.49 * *$ & $.47 *$ & $.36 * *$ & $.58 * *$ & $.51 * *$ \\
\hline 3. Achievement & & & $.46^{* *}$ & $.48 * *$ & $.58 * *$ & $.75 * *$ & $.81 * *$ & $.78 * *$ & $.38 * *$ & $.60 * *$ & $.54 * *$ \\
\hline 4. Friendly & & & & $.63 * *$ & $.67 * *$ & $.49 * *$ & $.49 * *$ & $.40 * *$ & $.40 * *$ & $.42 * *$ & $.37 * *$ \\
\hline 5. Sensitivity & & & & & $.66 * *$ & $.50 * *$ & $.55 * *$ & $.49 * *$ & $.32 * *$ & $.49 * *$ & $.56 * *$ \\
\hline 6. Cooperative & & & & & & $.55 * *$ & $.63 * *$ & $.50 * *$ & $.44 * *$ & $.44 * *$ & $.45 * *$ \\
\hline 7. Trustworthy & & & & & & & $.75 * *$ & $.67 * *$ & $.49 * *$ & $.51 * *$ & $.53 * *$ \\
\hline 8. Work Ethic & & & & & & & & $.78 * *$ & $.46^{* *}$ & $.56 * *$ & $.52 * *$ \\
\hline 9. Thoroughness & & & & & & & & & $.33 * *$ & $.63 * *$ & $.61 * *$ \\
\hline 10. Emot. Stability & & & & & & & & & & $.31 * *$ & $.21 * *$ \\
\hline 11. Ideas & & & & & & & & & & & $.63 * *$ \\
\hline 12. Think Through & & & & & & & & & & & \\
\hline
\end{tabular}

Note. ${ }^{*} p<.05 ; * * p<.01$.

TABLE 4.

Fit Indices for the CFA Models of the Personality Dimensions

\begin{tabular}{lcccc}
\hline Model & RMSEA & TLI & CFI & SRMR \\
\hline Agreeableness three-factor model & .07 & .78 & .80 & .07 \\
Conscientiousness three-factor model & .07 & .80 & .81 & .06 \\
Emotional Stability one-factor model & .11 & .79 & .82 & .07 \\
Openness two-factor model & .07 & .83 & .84 & .06 \\
Extraversion three-factor model & .07 & .76 & .77 & .08 \\
\hline
\end{tabular}

TABLE 5.

Proportion of Dimensions Rated "Essential" and Validity of Dimensions

\begin{tabular}{lcccc}
\hline Dimension & Prop. "essential” & Discipline validity & Service validity & Absence validity \\
\hline Leadership & .47 & .09 & .34 & -.30 \\
Negotiation & .32 & .04 & .28 & $-.38^{*}$ \\
Achievement & .73 & -.29 & $.42^{*}$ & -.29 \\
Friendliness & .38 & .01 & .13 & -.30 \\
Sensitivity & .38 & -.06 & .30 & $-.36^{*}$ \\
Cooperativeness & .70 & -.02 & .20 & $-.47^{*}$ \\
Trustworthiness & .60 & $-.35^{*}$ & $.46^{*}$ & -.30 \\
Work ethic & .61 & $-.38^{*}$ & $.38^{*}$ & $-.34^{*}$ \\
Detail & .74 & -.28 & .12 & $-.37^{*}$ \\
Emot. stability & .38 & -.12 & $.37^{*}$ & $-.34^{*}$ \\
Generating ideas & .27 & -.18 & $.41^{*}$ & -.26 \\
Thinking & .54 & -.24 & -.30 \\
\hline
\end{tabular}

Note. Bolded dimensions had an average of $60 \%$ of more behaviors rated as "essential." HSGPA = high school grade point average; Discipline $=$ number of times disciplined; Service $=$ performance in customer-service apprenticeship training; Absence $=$ number of absences in the first-year class. ${ }^{*} p<.05$.

identified by the SMEs as "essential" to performing the job. The highlighted dimensions are those in which the SMEs identified the constituent behaviors as essential at least $60 \%$ of the time. In general, those personality dimensions identified as important by the PPRF were also related substantively with work-relevant criteria. The average correlation for the personality dimensions that mapped on to the job-related PPRF dimensions with performance outcomes was .34. The average correlation for the personality dimensions associated with the non-job-related traits with performance outcomes was .24. We take this as modest evidence that the selection of job-related personality dimensions results in 
greater validity than the use of personality dimensions not identified by SMEs as job related.

\section{CONCLUSIONS}

Nearly 20 years ago, Raymark et al. (1997) presented a public-domain, personality-based job analysis instrument: the PPRF. In short, the instrument provides a method for developing hypotheses about the relation between personality constructs and performance on the job. Despite the authors' hopes that the instrument would stimulate research, and provide practitioners with an instrument to supplement existing job analysis instruments, the dimensions used by the PPRF do not map well to existing personality taxonomies such as those used in the IPIP. Moreover, we lack evidence showing that the traits identified as job relevant by the PPRF have greater criterion-related validity than traits identified as job irrelevant.

The primary purpose of this article was to present a public-domain repository of work-related personality items that may be used to assess the 12 work-related Big Five subdimensions identified by the PPRF. Our illustrative study showed some encouraging evidence for the dimensionality of the item pool, as well as the validity of job-related dimensions. Subsequent research is needed to further establish the connection between PPRF dimension importance and the validity of that dimension when assessed using our corresponding personality items. Establishing a relation between job relatedness and validity will go a long way toward enhancing the attractiveness of personality testing from a content-validity point of view. In addition, further scale development work can be done to show the item pool's relation with existing personality instruments, as well as investigating further the internal structure of the item pool. We hope this brief article stimulates such work.

\section{REFERENCES}

Goffin, R. D., Rothstein, M. G., Rieder, M. J., Poole, A., Krajewski, H. T., Powell, D. M., ... \& Mestdagh, T. (2011). Choosing job-related personality traits: Developing valid personality-oriented job analysis. Personality and Individual Differences, 51(5), 646-651.

Goldberg, L. R. (1999). A broad-bandwidth, public domain, personality inventory measuring the lower-level facets of several five-factor models. Personality Psychology in Europe, 7, 7-28.

Hu, L., \& Bentler, P. M. (1999). Cutoff criteria for fit indexes in covariance structure analysis: Conventional criteria versus new alternatives. Structural Equation Modeling, 6, 1-55.

Raymark, P.H., Schmit, M.J., \& Guion, R.M. (1997).

Identifying potentially useful personality constructs for employee selection. Personnel Psychology, 50, 723736.

Saucier, G., \& Goldberg, L.R. (1996). The language of personality: Lexical perspectives on the five-factor model. In J.S. Wiggins (Ed.), The five-factor model of personality: Theoretical perspectives. New York, NY: Guilford.

RECEIVED 2/24/2015 ACCEPTED 3/2/2016 


\section{APPENDIX. Dimensions and Items in Personality Item Bank}

\begin{tabular}{|c|c|}
\hline Dimension & Items \\
\hline General leadership & $\begin{array}{l}\text { I take charge } \\
\text { I see myself as a good leader } \\
\text { I try to lead others } \\
\text { I want to be in charge } \\
\text { I wait for others to lead the way [neg] } \\
\text { I let others make the decisions [neg] } \\
\text { I like to have influence over others } \\
\text { I like to make decisions } \\
\text { I know how to motivate people } \\
\text { I assign tasks to those that can handle them } \\
\text { I can inspire people to follow me } \\
\text { I like having authority over others } \\
\text { I can organize people to get things done } \\
\text { I delegate things to others } \\
\text { I enjoy serving as leader }\end{array}$ \\
\hline Interests in negotiation & $\begin{array}{l}\text { I enjoy bargaining } \\
\text { I can represent my group's views to others } \\
\text { I can usually understand both sides of an issue } \\
\text { I can mediate in quarrels } \\
\text { I enjoy resolving disputes } \\
\text { I enjoy negotiating } \\
\text { I will sacrifice to reach a compromise } \\
\text { I can resolve conflicts } \\
\text { I am willing to compromise } \\
\text { I can help others reconcile their differences } \\
\text { I can bring contesting people together } \\
\text { I can see common ground in opposing views } \\
\text { I like to negotiate compromise }\end{array}$ \\
\hline Achievement striving & $\begin{array}{l}\text { I excel in what I do } \\
\text { I seek to be the best } \\
\text { I work on improving myself } \\
\text { I want to be the very best } \\
\text { I can push myself to achieve } \\
\text { I strive to achieve } \\
\text { I seek out opportunities } \\
\text { I need to achieve excellence } \\
\text { I enjoy feeling successful } \\
\text { I set high personal goals } \\
\text { I dislike challenges [neg] } \\
\text { I try to do my best in most things } \\
\text { I like to win } \\
\text { I value personal achievement } \\
\text { I prefer excellence rather than just being "good enough" }\end{array}$ \\
\hline Friendliness disposition & $\begin{array}{l}\text { I make people feel welcome } \\
\text { I can get along with most people } \\
\text { I make friends easily } \\
\text { People feel at ease around me } \\
\text { Others consider me friendly } \\
\text { I like meeting new people } \\
\text { I interact easily with others }\end{array}$ \\
\hline
\end{tabular}


Friendliness (continued)

I avoid meeting new people [neg]

I have a friendly disposition

I enjoy the company of others

People seem to like me

I enjoy talking to others

I put new acquaintances at ease

I start conversations with strangers easily

Sensitivity to interests of others

I sympathize with others' feelings

I feel others' emotions

I am not interested in other people's problems [neg]

I know how to comfort others

I think about others first

I respect others' feelings

I respect the opinions of others

I'm not really interested in others' interests [neg]

Others' well-being is of concern for me

I consider others' needs

I consider others' interests above my own

I do things to enhance the well-being of others

I try to comfort others when they are distressed

\begin{tabular}{ll}
\hline Cooperativ or collaborative work ten- & I'm eager to work with others \\
dency & I like to assist clients or customers \\
I prefer to work alone & I dislike group projects [neg] \\
& I like to be part of a team \\
& Team success is important to me \\
& Team success is more important than personal gain \\
& I will sacrifice for the team \\
& I enjoy collaborating on work tasks \\
& I like being part of a group with a common goal \\
& I think groups are good for solving problems \\
& I am able to cooperate with others \\
& I work well with others \\
\hline General trustworthiness & I keep my promises \\
& I do what I say \\
I seldom forget appointments & I don't see things through [neg] \\
I break my promises [neg] & I abuse people's confidence [neg] \\
I can be counted on \\
I'm not good at keeping secrets [neg] \\
People see me as trustworthy \\
I'm trusted with money or property \\
I can be counted on to keep information confidential \\
People know I tell the truth \\
I follow through when I make promises \\
My word can be trusted \\
I have a reputation for being fair \\
I accomplish my work on time \\
I start tasks right away \\
I see that rules are observed \\
I put work above pleasure \\
I do more than my boss asks of me \\
\hline Adherence to a work ethic
\end{tabular}


Adherence to a work ethic (continued) I get chores done right away

I get to work at once

I follow directions

I expect dedicated work from others

I am always on time

I do just enough to get by [neg]

I'm a diligent worker

I have a strong work ethic

I don't like laziness

I try to be a loyal worker

Thoroughness and attentiveness to details

I pay attention to details

I continue until everything is perfect

I dislike imperfect work

I am exacting in my work

I want everything to be "just right"

I want every detail taken care of

I routinely double check my work

I seldom notice details [neg]

I'm a perfectionist

I don't worry about details [neg]

I take a meticulous approach to work

I pay attention to details others might overlook

I inspect thoroughly what others do

I think of myself as a careful worker

I don't waste time worrying about details [neg]

Emotional stability

I rarely get irritated

I remain calm under pressure

I am not easily bothered by things

I seldom take offense

I am not easily frustrated

I seldom get emotional

I am relaxed most of the time

I don't worry about things that have already happened

I can accept criticism without getting upset

I get stressed out easily [neg]

I get irritated easily [neg]

I get caught up in my problems [neg]

I am easily offended [neg]

I am guided by my moods [neg]

I don't react well when things go wrong [neg]

Desire to generating ideas

I am full of ideas

I like to think up new ways of doing things

I think up new ideas

I come up with alternatives

I have a good imagination

I have excellent ideas

I get excited by new ideas

I do not have a good imagination [neg]

I like to develop new ideas

I like to find unusual solutions to problems

I prefer jobs that require innovations

I find it easy to think of new ways to approach problems

I am creative 
Tendency to think things through I spend time reflecting on things

I like to solve complex problems

I enjoy thinking about things

I can spot faulty reasoning

I think deeply about things

I avoid philosophical discussions [neg]

I am not interested in speculating about things [neg]

I don't like to ponder over things [neg]

I hate to analyze things too much [neg]

I think about consequences of actions

I tend to go through procedures in my mind before actually starting a task

I evaluate information before accepting it

I try to figure out what's going to happen before making a decision

I question things I don't understand

Note. The personality item bank may also be obtained using this link: https://www.bgsu.edu/arts-and-sciences/psychology/ services/personality-related-position-requirements-form-.html. 